\title{
Structure-texture peculiarities influence on petrophysical properties of Neftekumsk carbonate sediments
}

\author{
Natalia Yeriomina ${ }^{1, *}$, Vladimir Gridin ${ }^{1}$, Zinaida Sterlenko ${ }^{1}$, Yelena Tumanova ${ }^{1}$, Katerina \\ Chernenko ${ }^{1}$ \\ ${ }^{1}$ Institute of oil and gas, North-Caucasus federal university, Kulakova avenue, 16, 355035, Stavropol, \\ Russia
}

\begin{abstract}
The analysis of structure-texture peculiarities of carbonate sediments of Neftekumsk' reservoir within the limits of Zimne-StavkinskoPravoberezhny field was realized in the field of massive bioherm buildups and interreef lowerings in accordance with data of the core analyses. The existing pore space was divided into structure-texture classes. The correlations between petrofabrics and petrophysical parameters were determined. The received data can be used for describing of the threedimensional distribution of petrophysical properties with the aim to increase the quality of three-dimensional (3-D) geological models.
\end{abstract}

\section{Introduction}

Carbonate collectors (reservoirs) have the very complex structure, the process of geological-hydrodynamic modeling is very difficult because of the very high degree of heterogeneity. Heterogeneity in the area of deposits is defined by sediment condition for carbonate sediments and their diagenetic transformation. To increase the assurance of 3-D geological modeling the authors of the article have studied the space distribution of petrophysical properties such as porosity and permeability.

Tectonically Velichayevsko-Maksimokymsky oil-and-gas accumulation zone is relating to the so-named large earthen wall of the east-west trending. The main oil deposits in the carbonate sediments of Neftekumsk's assise are confined to the VelichayevskoMaksimokymsky earthen wall (Tomashev, 2011). The nature of Neftekumsk' natural carbonate reservoir is of argumentative issue; it is possible that there are alternative models. The analysis of drilling data and wells testing, the synthesizing of field-geophysical materials and seismic time sections testify the next model: Neftekumsk's sediments are fully-developed reef systems, they were dynamically evolving in space and time; their peculiar features are the wide set of facies, reflecting transgressive and regressive cycles of sedimentation. The patterns' study of hydrocarbon space distribution on the investigated area allowed concluding that commercial oilcontent of Neftekumsk's sediments is connected with dolomitized organogenic buildups.

\footnotetext{
* Corresponding author: yeriominasai@mail.ru
} 
Sediments of Neftekumsk's assise in the East Stavropolie divided into the composing types of rocks according to the sedimentogenesis conditions, i.e. lithogenous types of rocks are marked out depending on their genesis: rocks of autochthonous (in-place) carbonate deposition (organogenic buildups), parautochthonous and allochthonous (transported) carbonate deposition.

\section{Samples and methods}

In a view of base development for litho-facies interpretation, the detailed studying of researches results of core materials was held. The authors have analyzed the results of core samples (more 300) descriptions from 40 wells. Two research methods were applied: cluster and structure-texture (rock-fabric) analyses.

\section{Cluster analysis}

The cluster analysis applying in statistic researches in objects classification and realizing in computer program (software) Statistica can be used to choose rocks types according to the sedimentogenesis conditions [1].

The grouping method K-MEANS CLUSTERING was applied. Before classification the syncretic characteristics were standardized.

As diagnostic variables there were used: core depth, open porosity, permeability in two directions - regular and perpendicular to the bedding, carbonate content, grade of carbonate content value $(1-0-5 \% ; 2-5-25 \% ; 3-25-50 \% ; 4-50-75 \% ; 5-75-95 \% ; 6-95-100 \%)$; range of lithogenic composition of rocks (6 - limestones, 5 - dolomites, 4 -marls, 1-3clastic sedimentary rocks) (Figure 1).

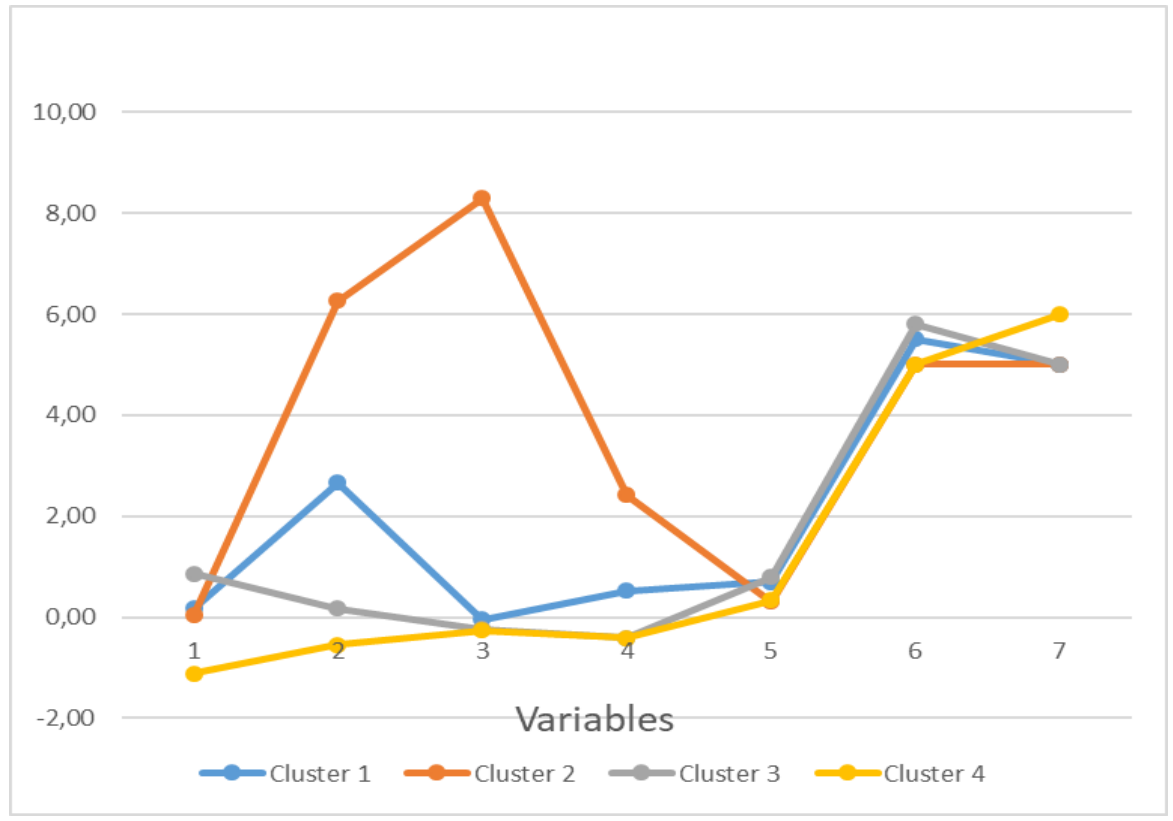

Fig. 1 Average values graphics of diagnostic variables for the marked classes. (Symbols: 1 - core depth; 2 - open porosity; 3 - permeability - regular to the bedding; 4 - permeability - perpendicular to the bedding; 5 - carbonate content; 6 - grade of carbonate content value; 7 - range of lithogenic composition of rocks. 
Results of cluster analysis for characteristics of Neftekumsk' natural reservoir within the limits of Zimne-Stavkinsko-Pravoberezhny field (Velichayevsko-Maksimokymsky oiland-gas accumulation zone) allowed us to mark out four classes that correspond to lithogenic rock types (Figure 1).

The highest average values of reservoir properties were defined for the first and the second clusters correlated mainly to the middle part of the section. Rocks primarily consist of dolomites.

The third and the fourth clusters situating in the upper and the lower parts of the section correspondently are characterized by more low average values of reservoir properties. These clusters differ in the lithological composition. In the upper part of cross-section dolomites predominates, in the lower part - limestones.

The analogy observes between clusters' characteristics and lithogenic types of rock: the first and the second classes are relating with rocks of autochthonous carbonate deposition, but the third and the fourth - with rocks complexes of parautochthonous and allochthonous carbonate deposition.

\section{Structure-texture analysis}

The cluster analysis allows characterizing the vertical distribution of petrophysical characteristics enough quickly and efficiently taking into consideration their genetic origin. However, to make 3-D geological model that can be quantitatively presented through petrophysical parameters, it is necessary to distribute data in the interwell space $[2,3,4,5]$. In view of this Jerry F. Lucia proposed a structure-texture method [6,7] to build a reservoircollector model providing the four stages:

1) to create 3-D chronostratigraphic framework and mapping the sequences and highfrequency cycles;

2) to define the vertical succession of rock fabrics and rock-fabric flow layers;

3) to develop a formula to recalculate porosity in permeability for every class of structure-texture picture;

4) «filling» the interwell environment with petrophysical properties.

The authors of this research have studied the structure-texture peculiarities of carbonate sediments of Velichayevsko-Maksimokymsky oil-and-gas accumulation zone in the area of massive bioherm buildups and interreef lowerings in accordance with data of the core analyses (the 3 stage). To realize this process, the abovementioned rock volume was used.

The three structure-texture groups describing by Lucia and according to Dunham classification (1962) defined the presence of the three petrophysical classes (Figure 2). Classes 1 and 2 consist of three petrofabrics (every class), class 3 consists of 2 petrofabrics. Grainstones, dolograinstones, and large crystalline dolostones all have similar petrophysical properties that are characterized by petrophysical class 1. Grain-dominated packstones, fine and medium crystalline grain-dominated dolopackstones, and medium crystalline muddominated dolostones all have similar petrophysical properties that are characterized by petrophysical class 2. Mud-dominated limestones (mud-dominated packstone, wackestone, and mudstone) and fine crystalline mud-dominated dolostones all have similar petrophysical properties that are characterized by petrophysical class 3[7]. 


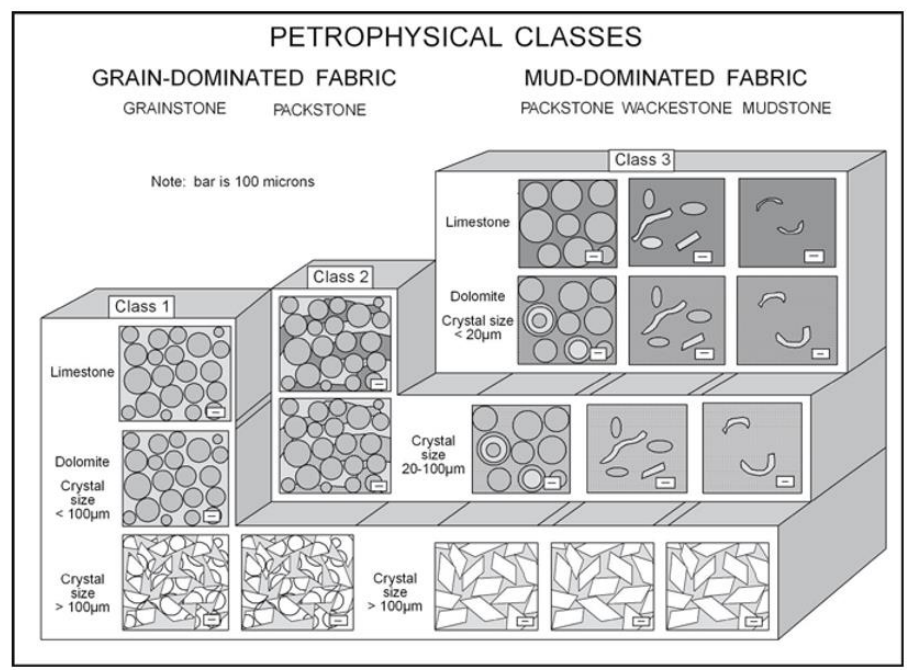

Fig. 2 A block-diagram illustrating the relationship between structure-texture and petrophysical classes.

Nowadays in Russia, Dunham (1962) and Embry and Klovan (1971) [8] classification with the application of the modified classifications $[9,10,11]$ was not applied in the practice of carbonate rocks describing.

That is why the authors tried to classify carbonate rocks of Neftekumsk' assise by Dunham (1962) and Embry and Klovan (1971): according to the data of core description the authors have realized the samples differentiation on petrophysical classes. Core with vuggy and fracture porosity is conditionally relating by the authors to the class 4 .

Let's show the characteristics of every marked petrophysical classes of Neftekumsk' assise sediments.

Class 1 . Rocks samples are practically absent. It is presented by limestones, very strong, large (coarse)-grained. Porosity is $0.04 \%$, there is no information about permeability.

Class 2. This class includes 54 core samples, open porosity was determined for 44 core samples (minimal $-0.01 \%$, maximal $-0.07 \%$, average $-0.03 \%$ ). There are only two permeability values (determined by regular direction to the bedding) - minimal $0.3 \cdot 10^{-3}$ $\mu \mathrm{m}^{2}$, maximal $1.4 \cdot 10^{-3} \mu \mathrm{m}^{2}$, average $-0.85 \cdot 10^{-3} \mu \mathrm{m}^{2}$. This class is dominantly presented by fine-grained limestones. The absence of sufficient data volume (in which porosity and permeability were simultaneously determined) did not allow making the relationship for this petrophysical class.

Class 3. This class includes 93 core samples. Open porosity was determined for 66 core samples (minimal $0.01 \%$, maximal $0.06 \%$, average $0.024 \%$ ), there are three representative permeability values (minimal $0.02 \cdot 10^{-3} \mu \mathrm{m}^{2}$, maximal $0.1 \cdot 10^{-3} \mu \mathrm{m}^{2}$, average $-0.05 \cdot 10^{-3} \mu \mathrm{m}^{2}$ ). This class is dominantly presented by limestones - close-grained, strong, crystalline and cryptocrystalline.

The equation of porosity and permeability relationship is shown below (Formula 1) and presented on Figure 3:

$$
k_{\text {permeability }}=10^{6} k_{\text {porosity }}{ }^{4,251}, R=0.9,
$$

where, $\mathrm{k}_{\text {permeability }}$ - permeability determined by regular direction to the bedding, $10^{-3}$ $\mu \mathrm{m}^{2} ; \mathrm{k}_{\text {porosity }}$ - open porosity, fractions; $\mathrm{R}$ - correlation of relationship coefficient. The same parameters with the same units were used in the equations given below. 


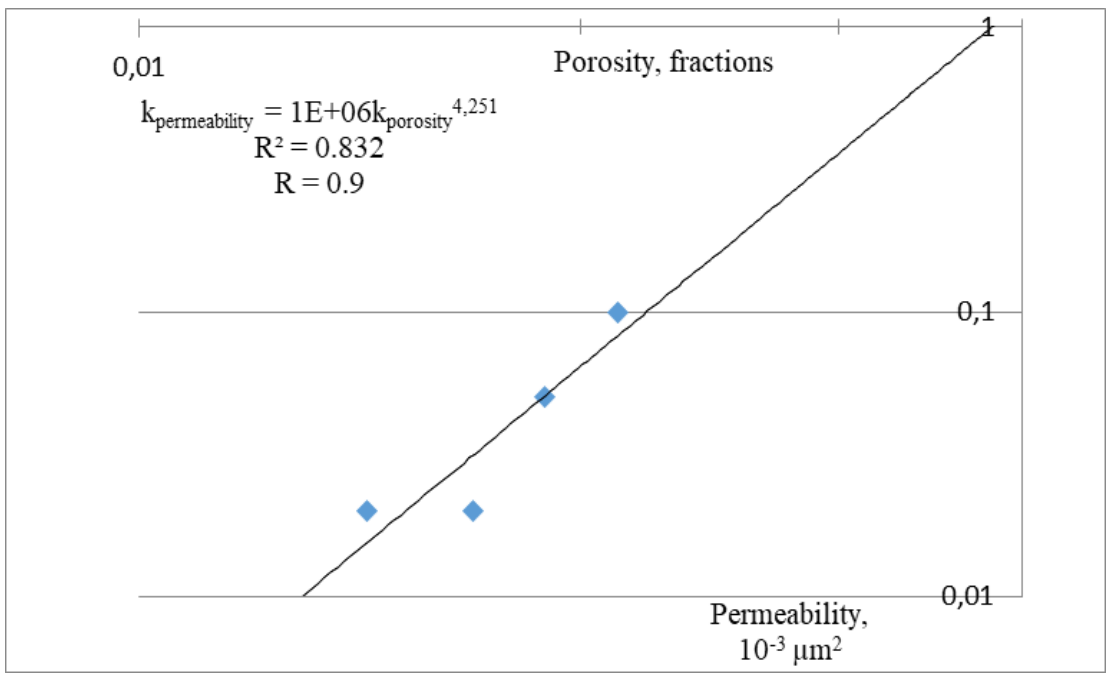

Fig. 3 Permeability-porosity cross plot for carbonate sediments of Neftekumsk' reservoir within the limits of Zimne-Stavkinsko-Pravoberezhny field (dominantly limestones - close-grained, strong, crystalline and cryptocrystalline, class 3 ).

Class 4. This class includes 129 core samples. Open porosity was determined for 125 core samples (minimal $0.01 \%$, maximal $0.18 \%$, average $0.03 \%$ ). There are 45 permeability values (determined by regular direction to the bedding) - minimal $0.01 \cdot 10^{-3}$ $\mu \mathrm{m}^{2}$, maximal $387.8 \cdot 10^{-3} \mu \mathrm{m}^{2}$, average $-10.56 \cdot 10^{-3} \mu \mathrm{m}^{2}$. This class is dominantly presented by intensively fractured limestones and dolomites.

The equation of porosity and permeability relationship is shown below (Formula 2) and presented on Figure 4:

$$
k_{\text {permeability }}=158.68 k_{\text {porosity }}{ }^{1,921}, R=0.631
$$

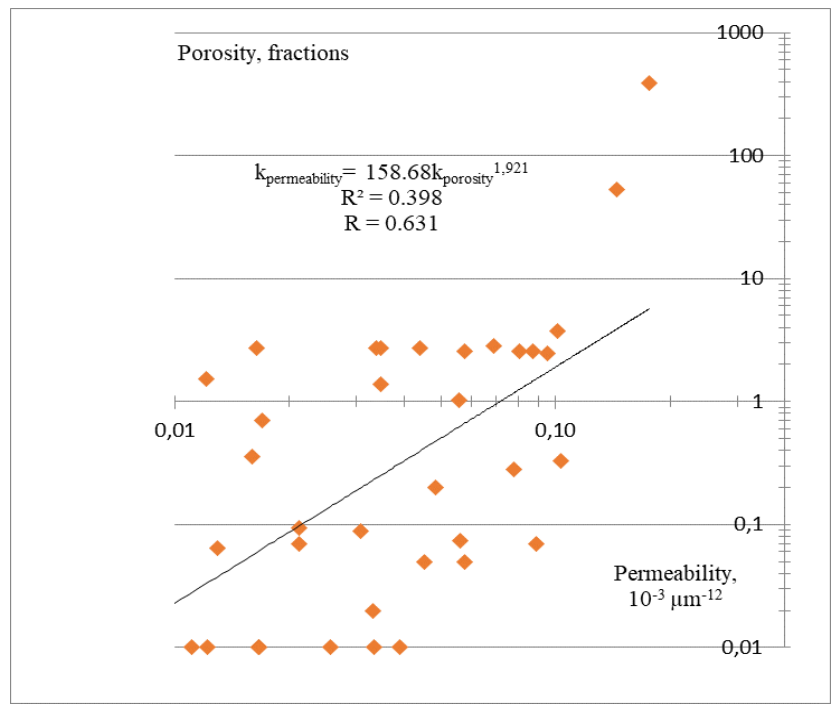

Fig.4 Permeability-porosity cross plot for carbonate sediments of Neftekumsk' reservoir within the limits of Zimne-Stavkinsko-Pravoberezhny field (dominantly presented by intensively fractured limestones and dolomites, class 4). 
The determined relationships have the high correlation ratio $(\mathrm{R}>0.63)$. Most of samples of 1-3 classes have permeability lower than 1 millidarcy $\left(\begin{array}{llll}0.1 & 10^{-3} & \mathrm{~m}^{2}\end{array}\right)$; according to the rocks researches of the East Fore-Caucasus they are not the collectors. And only dominantly fractured and vuggy varieties of rocks in class 4 (where considerable portion of samples with permeability more than 1 millidarcy) are the collectors.

Consequently, the oil collectors of productive ledges in Zimne-StavkinskoPravoberezhny field according to their reservoir parameters are relating to the collectors of average and low quality.

\section{Conclusions}

After realizing researches the authors were managed to mark out the four structure-texture (petrophysical) classes, for them the equations of permeability (determined by regular direction to the bedding) - open porosity relationship were built. The obtaining results are used to predict the space distribution of petrophysical properties of Neftekumsk' sediments in Zimne-Stavkinsko-Pravoberezhny field.

Thus, the core samples classifying as the fourth petrophysical class are confined to the zones of autochthonous carbonate deposition. They are characterized by the increased fractured capacity. That is why, the main objects of additional exploration can be considered the undrilled zones of autochthonous carbonate rocks associating with zones of rocks distributions of the fourth petrophysical class.

\section{References}

1. N.V. Yeriomina, Z.V. Sterlenko, Ye.Yu. Tumanova, K.I. Chernenko, VIII Conference "Contemporary Issues of Geology, Geophysics and Geo-ecology of the North Caucasus", 305-309, Atlantis Press (2019) DOI: 10.2991/ciggg-18.2019.58

2. G.E. Fogg, F.J. Lucia, R.K. Senger, Reservoir Characterization 2, 355-381, (1991) doi: 10.1016/B978-0-12-434066-4.50020-5

3. Sh. Pourmohammadi, S. Hetland, K. Spildo, A. Skauge, SPE/EAGE Reservoir Characterization and Simulation Conference (2007) doi:10.2523/111433-ms

4. G. Fogg, F.J. Lucia, The University of Texas at Austin, Texas (1990) doi:10.23867/ri0190d

5. A. Lønøy, 1st International Petroleum Conference and Exhibition Shiraz (2009) doi:10.3997/2214-4609.20145902

6. F.J. Lucia, J.W. Jr., S.C. Ruppel, AAPG Hedberg Research Conference, El Paso, Texas (2004) doi: 10.2523/70063-MS

7. A. Lønøy, AAPG Bulletin 90, no. 9 (2006) doi:10.1306/03130605104

8. A.F. Embry, J.E. Klovan, Bulletin of Canadian Petroleum Geology 19 (4), 30-781 (1971) doi: ISSN 0007-4802

9. S.W. Lokier, M. Al Junaibi, Sedimentology 63 (7), 1843-1885 (2016) doi: 10.1111/sed.12293. ISSN 1365-3091

10. R.L. Folk, AAPG Bulletin 43 (1), 1-38 (1859) doi:10.1306/0bda5c36-16bd-11d7$\underline{8645000102 \mathrm{c} 1865 \mathrm{~d} \text {. ISSN 0149-1423 }}$

11. V.P. Wright, Sedimentary Geology 76 (3-4), 177-185 (1992)doi:10.1016/0037$\underline{0738(92) 90082-3}$ 